\title{
Obesity-Related Genetic Variants and their Associations with Physical Activity
}

\author{
Harold Lee ${ }^{1 *}$, Garrett I. Ash², Theodore J. Angelopoulos ${ }^{3}$, Paul M. Gordon ${ }^{4}$, Niall M. Moyna ${ }^{5}$, Paul S. Visich ${ }^{6}$, \\ Robert F. Zoeller ${ }^{7}$, Heather Gordish-Dressman ${ }^{8}$, Ved Deshpande ${ }^{9}$, Ming-Hui Chen ${ }^{9}$, Paul D. Thompson ${ }^{10}$, \\ Eric P. Hoffman ${ }^{8}$, Joseph M. Devaney ${ }^{8}$ and Linda S. Pescatello ${ }^{11,2}$
}

\begin{abstract}
Background: Meta-analysis of genome-wide association studies identified obesity-related genetic variants. Due to the pleiotropic effects of related phenotypes, we tested six of these obesity-related genetic variants for their association with physical activity: fat mass and obesity-associated (FTO)(rs9939609)T>A, potassium channel tetramerization domain containing (KCTD15) (rs1 1084753)G>A, melanocortin receptor4 (MC4R)(rs 17782313)T>C, neuronal growth regulator 1 (NEGR1)(rs2815752)A>G, SH2B adapter protein 1 (SH2B1)(rs7498665)A>G, and transmembrane protein18 (TMEM18)(rs6548238)C $>$ T.

Method: European-American women $(n=263)$ and men $(n=229)\left(23.5 \pm 0.3\right.$ years, $\left.24.6 \pm 0.2 \mathrm{~kg} / \mathrm{m}^{2}\right)$ were genotyped and completed the Paffenbarger physical activity Questionnaire. Physical activity volume in metabolic energy equivalents [MET]-hour/week was derived from the summed time spent (hour/week) times the given MET value for vigorous, moderate, and light intensity physical activity, and sitting and sleeping, respectively. Multivariable adjusted [(age, sex, and body mass index (BMI)] linear regression tested associations among genotype (dominant/ recessive model) and the log of physical activity volume.

Result: MC4R (rs17782313)T>C explained $1.1 \%(p=0.02)$, TMEM18(rs6548238)C>T $1.2 \%(p=0.01)$, and SH2B1 (rs7498665)A>G $0.6 \%(p=0.08)$ of the variability in physical activity volume. Subjects with the MC4R C allele spent $3.5 \%$ less MET-hour/week than those with the TT genotype $(p=0.02)$. Subjects with the TMEM18 T allele spent $4.1 \%$ less MET-hour/week than those with the CC genotype $(p=0.01)$. Finally, subjects with the SH2B1 GG genotype spent $3.6 \%$ less MET-hour/week than A allele carriers $(p=0.08)$.

Conclusion: Our findings suggest a shared genetic influence among some obesity-related gene loci and physical activity phenotypes that should be explored further. Physical activity volume differences by genotype have public health importance equating to 11-13 lb weight difference annually.
\end{abstract}

\section{Key Points}

- As we hypothesized, the obesity-related SNPs $M C 4 R$ (rs17782313) $\mathrm{T}>\mathrm{C}$ and TMEM18 (rs6548238) $\mathrm{C}>\mathrm{T}$ significantly associated with physical activity volume, while SH2B1 (rs7498665) A $>$ G trended towards significance.

- $M C 4 R$ (rs17782313) T>C, TMEM18 (rs6548238) $\mathrm{C}>\mathrm{T}$, and SH2B1 (rs7498665) A $>\mathrm{G}$ accounted for $\sim 1 \%$ of the variance in physical activity levels each.

\footnotetext{
* Correspondence: harold_lee@brown.edu

'Department of Behavioral and Social Sciences, Brown University School of Public Health, Box G-S121-2, Providence, RI 02912, USA

Full list of author information is available at the end of the article
}

- Our findings have public health significance as the genotype differences in physical activity volume we found ranged from 10.1 to 11.8 MET-hour/week equating to a potential weight differential of 10.8-12.7 lb annually.

\section{Background}

Overweight and obesity are an epidemic affecting more than $68.5 \%$ of U.S. adults [1]. To curb this alarming statistic, a plethora of weight loss strategies have been proposed ranging from counseling [2] and text messaging [3] to incentivizing [4] and pharmaceutical interventions [5]. Many of these strategies have proven efficacious in the short term, but less successful in long-

\section{实 Springer}


term weight loss and maintenance of that weight loss. Physical activity is not only effective in achieving weight loss, but also essential in predicting successful weight loss maintenance [6, 7]. Therefore, the American College of Sports Medicine (ACSM) recommends 150-250 min/ week of moderate intensity physical activity for weight loss, and even greater amounts for weight loss maintenance $[8,9]$. However, less than half $(49.1 \%)$ of U.S. adults meet the ACSM physical activity recommendations, and $23.7 \%$ of U.S. adults do not participate in any leisure time physical activity [10]. Despite the important role of physical activity in obesity treatment and its promise for long-term weight loss maintenance, it is not clear why some individuals are more likely to participate in habitual physical activity than others to maintain a healthy body weight.

Twin and family studies have shown that genetic predispositions contribute to overweight and obesity [11-15] with heritability accounting for $37-78 \%$ of the variance in obesity-related phenotypes. In 2009, the Genetic Investigation of Anthropometric Traits (GIANT) consortium conducted a meta-analysis of genome-wide association studies (GWAS) involving 32,387 individuals of European ancestry and identified eight genetic variants that associated with body mass index (BMI) [16]. These single nucleotide polymorphisms (SNPs) were fat mass and obesity-associated (FTO) (rs9939609) T>A, glucosamine-6 phosphate deaminase 2 (GNPDA) (rs10938397) A $>$ G, potassium channel tetramerization domain containing (KCTD15) (rs11084753) G>A, melanocortin receptor 4 (MC4R) (rs17782313) $\mathrm{T}>\mathrm{C}$, mitochondrial carrier homo$\log 2$ (MTCH2) (rs10838738) A $>$ G, neuronal growth regulator 1 (NEGR1) (rs2815752) $\mathrm{A}>\mathrm{G}, \mathrm{SH} 2 \mathrm{~B}$ adapter protein 1 (SH2B1) (rs7498665) A $>$ G, and transmembrane protein 18 (TMEM18) (rs6548238) C>T.

There is a growing literature showing the important effect-mediation that physical activity has on the genetic predispositions to be obese $[15,17-19]$. The genetic variants examined in these studies were mainly those identified in the GWAS by the GIANT consortium to associate with BMI. We are part of an interdisciplinary research team that has completed a large exercise genomics study, Functional Single Nucleotide Polymorphisms Associated with Human Muscle Size and Strength (FAMuSS, NIH R01 NS40606-02). Our colleague, Orkunoglu-Suer et al. [20], previously examined the eight SNPs identified by the GIANT consortium for their association with obesity-related phenotypes at baseline and in response to resistance training in the FAMuSS cohort. They found sex-specific associations with MC4R ( $r$ 17782313) $\mathrm{T}>\mathrm{C}$ and BMI; TMEM18 (rs6548238) $\mathrm{C}>\mathrm{T}$ and baseline subcutaneous fat volume; and FTO (rs9939609) $\mathrm{T}>\mathrm{A}$ and SH2B1 (rs7498665) A $>\mathrm{G}$ and the subcutaneous fat volume response to resistance training [20].

In our previous work [20] and that of others [15, 17-19], the effect-medication of physical activity on genetic predispositions for overweight and obesity was examined. What was not investigated using this approach is the possibility of obesity-related SNPs influence physical activity behavior (Fig. 1). Pleiotropy refers to the shared genetic influence of related phenotypes [21, 22]. Based upon the concept of pleiotropy, we speculate that the GWASidentified obesity-related SNPs by the GIANT consortium may associate with physical activity phenotypes. Indeed, there is biological plausibility for doing so as the GWAS SNPs found by the GIANT consortium are expressed in hypothalamus where energy homeostasis is regulated. In addition, recent work in animals has shown that the control of voluntary movement resides in similar central neural pathways as energy intake [23-25]. Therefore, it is plausible that the central nervous system would be an upstream region where these GWAS SNPs share a common biological influence on both obesity and physical activity phenotypes.

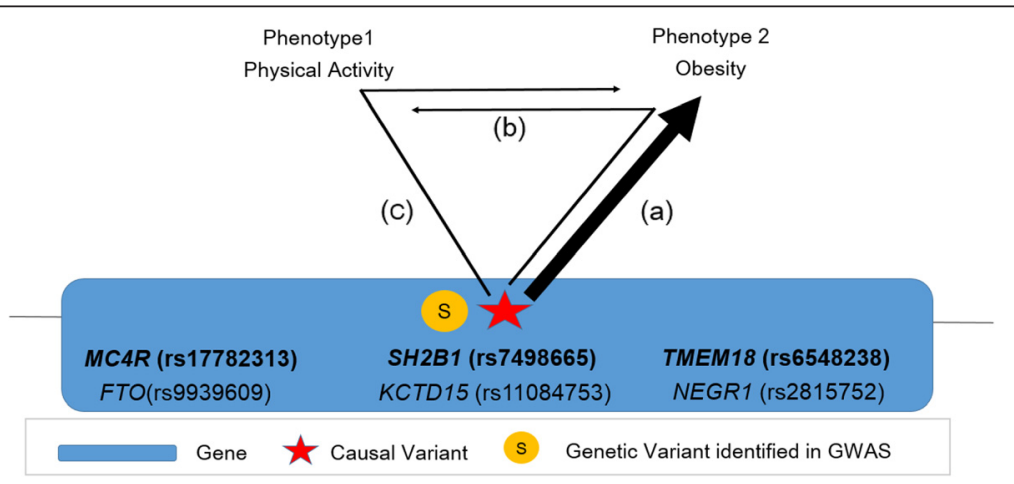

Fig. 1 A hypothetical model of the pleiotropy between obesity-related gene loci and physical activity phenotypes. a s GWAS-identified gene loci associated with BMI [16]. Two possible explanations supporting the concept of pleiotropy or the shared genetic influence of related phenotypes: $\mathbf{b}$ An individual with genetic predispositions to obesity is less physically active due to their obesity as discussed by Richmond et al. [33] and others [34, 35]; or (c) an individual with genetic predispositions to be less physically active becomes overweight to obese [32, 37] 
Therefore, the purpose of the present study was to investigate the six obesity-related SNPs identified in the GWAS by the GIANT consortium for their association with habitual physical activity that were in Hardy Weinberg Equilibrium in the FAMuSS cohort. We hypothesized that these GWAS obesity-related genetic variants would associate with habitual physical activity.

\section{Methods}

\section{Overview}

This substudy is part of the larger FAMuSS (NIH R01 NS40606-02). FAMuSS was the first systematic study to examine how physiological responses to resistance training are modified by genes and the environment [26]. The institutional review boards from the ten institutions involved with FAMuSS approved the study protocol. All procedures followed were in accordance with the ethical standards of the responsible committee on human experimentation (institutional and national) and with the Helsinki Declaration of 1975, as revised in 2013. Informed consent was obtained from all patients for being included in the study. The experimental design of FAMuSS has been described elsewhere so that only the methods pertaining directly to this substudy will be described in detail [26].

\section{Subjects}

Potential FAMuSS participants were recruited from the eight resistance training sites via strategic flyer placement and in-house listserv and radio announcements. Subjects were excluded if they were $<18$ or $>40$ years and if they were taking any medications known to affect skeletal muscle function such as corticosteroids, antihypertensive or anti-lipidemic medications, anabolic steroids, diuretics, arthritis medications (Vioxx, Celebrex), Depo-Provera contraceptive injection, nasal inhalers (Clenbuterol and Rhinocort), lithium, or chronic use of non-steroidal anti-inflammatory drugs. In addition, because the primary aim of FAMuSS was to examine the influence of genetic variation on the muscle size and strength response to resistance training, individuals who reported regular participation in resistance training within the past 12 months prior to enrollment or performed occupational or recreational physical activity that involved heavy use of the upper body were also excluded.

\section{Body Composition}

Anthropometric measures were collected using standardized protocols among the testing sites. Height and weight were measured using a calibrated wall-mounted stadiometer and scale, respectively, from which BMI was calculated $\left(\mathrm{kg} / \mathrm{m}^{2}\right)$.

\section{Physical Activity}

Subjects completed the Paffenbarger physical activity questionnaire during their initial visit to assess weekly physical activity over the last year. The Paffenbarger physical activity questionnaire is an eight-item instrument validated among populations similar to the FAMuSS cohort that is used to measure self-reported weekly duration and intensity of physical activity [27, 28]. Physical activity volume in metabolic energy equivalents (MET)-hour/week was derived from the summed time spent (hour/week) times the given MET value for vigorous, moderate, and light intensity physical activity, and sitting and sleeping, respectively [29].

\section{Genotyping}

A sample of whole blood was obtained from each subject, refrigerated, and sent to the Children's National Medical Center Research (Washington, DC). DNA was isolated from peripheral blood lymphocytes with the Gentra Puregene DNA extraction kit (Qiagen, Valencia, CA) and genotyping was completed using Taqman assays from ABI (Foster City, CA). Allele-specific PCR reactions for each polymorphism included 20 ng DNA, $900 \mathrm{nM}$ forward and reverse PCR primers, $200 \mathrm{nM}$ fluorescent allele discrimination probes (common allele FAM labeled; rare allele VIC labeled), and TaqMan ${ }^{\oplus}$ Universal PCR Master Mix, No AmpErase ${ }^{\bullet}$ UNG (Applied Biosystems, Foster City, CA, USA) in a final volume of $25 \mu \mathrm{l}$. The PCR and fluorescent ratio profile was generated after $10 \mathrm{~min}$ at $95{ }^{\circ} \mathrm{C}$ (denaturation), 44 cycles of $15 \mathrm{~s}$ at $92{ }^{\circ} \mathrm{C}$, and $1 \mathrm{~min}$ at an annealing temperature of $60{ }^{\circ} \mathrm{C}$. The end point fluorescent readings were analyzed using an ABI 7900HT and the two alleles were called using Sequence Detection System (SDS V 2.3 software; Applied Biosystems, Foster City, CA) and checked manually [30].

In this substudy, 492 subjects were genotyped for the following SNPs identified in the GWAS by the GIANT consortium to associate with BMI that were also in Hardy Weinberg Equilibrium in the FAMuSS cohort (Table 1) (13): FTO (rs9939609; $n=483) \mathrm{T}>\mathrm{A}$, KCTD15 $(\mathrm{rs} 11084753 ; n=490) \mathrm{G}>\mathrm{A}, M C 4 R(\operatorname{rs} 17782313 ; n=480)$ $\mathrm{T}>\mathrm{C}, \quad$ NEGR1 $\quad(\mathrm{rs} 2815752 ; \quad n=491) \quad \mathrm{A}>\mathrm{G}, \quad S H 2 B 1$ (rs7498665; $n=489$ ) A $>\mathrm{G}$, and TMEM18 (rs6548238; $n=490) \mathrm{C}>\mathrm{T}$.

\section{Statistical Analysis}

Descriptive analyses were performed for all study variables. No SNP was in linkage disequilibrium with the other $\left(r^{2}<0.001\right)$. To reveal associations among genotype (dominant/recessive model) and MET-hour/week, multivariable adjusted (age, sex, and BMI) linear regression was used. Then the partial (Type-3) R-square values for the independent variables were computed. In the 
Table 1 Chi-square $\left(x^{2}\right)$ and allelic frequencies of single nucleotide polymorphisms examined in the current study

\begin{tabular}{lllllll}
\hline Nearest gene & RefSeq\# & Alleles (+/-) & $x^{2}$ & $p$ & $q$ & $p$ value \\
\hline FTO & rs9939609 & T/A & 0.74 & 0.40 & 0.60 & 0.39 \\
MC4R & rs17782313 & T/C & 0.04 & 0.21 & 0.79 & 0.83 \\
NEGR1 & rs2815752 & A/G & 0.71 & 0.65 & 0.35 & 0.39 \\
SH2B1 & rs7498665 & A/G & 0.04 & 0.61 & 0.39 & 0.84 \\
KCTD15 & rs11084753 & G/A & 0.02 & 0.66 & 0.34 & 0.88 \\
TMEM18 & rs6548238 & C/T & 0.08 & 0.82 & 0.18 & 0.78
\end{tabular}

FTO fat mass and obesity-associated gene, MC4R Melanocortin 4 receptor, NEGR1 neuronal growth regulator $1, K C T D 15$ potassium channel tetramerization domain containing 15, SH2B1 Src homology 2 B adapter protein 1, TMEM18 transmembrane protein 18 . $\mathrm{df}=1$ for all analyses

regression model, log-transformation was considered for the physical activity volume outcome variable to satisfy the underlying assumption (=normality). To estimate the actual MET-hour/week difference among genotypes, the coefficient obtained from the regression model was back transformed (e.g., $\mathrm{e}^{-0.036}=0.964$ ), and multiplied by the mean MET-h.wk ${ }^{-1}$ (i.e., 287.4 MET-hour/week) among the FAMuSS cohort (Table 2). Linear regression analyses were performed using the $\mathrm{R}$ Core Team (2015) for Windows (Vienna, Austria); and descriptive statistics were performed using the Statistical Package for the Social Sciences (SPSS) 14.0 for Windows (Chicago, IL, USA). We ran a power calculation based on the R-square difference between the full model vs. the three genetic variants (MC4R, TMEM18, SH2B1) using Statistical Analysis System (SAS) 9.1.3 for Windows (Cary, NC, USA). Accordingly, we had $92.5 \%$ power with an alpha $<0.05$ to detect phenotype-genotype differences with three genetic variants and physical activity volume.

\section{Results}

\section{Subject Characteristics}

The sample consisted of healthy, young EuropeanAmerican men and women (Table 2) with a BMI level that reflected the larger FAMuSS cohort [20, 26], and the general age-matched population from which they were recruited [1]. While age did not differ by sex $(p>$ $0.05)$, men had a higher BMI than women $(p<0.001)$. The self-reported sitting time $(6.4 \mathrm{~h} /$ day or $40 \%$ of waking time) among this FAMuSS subsample was slightly lower than the average American adults' sitting time (60\% of waking time) [31].

\section{Genetic Predictors of Physical Activity Volume (MET-hour/week)}

Multivariable linear regression model revealed that MC4R (rs17782313) $\mathrm{T}>\mathrm{C} \quad(p=0.02)$ and TMEM18 (rs6548238) $\mathrm{C}>\mathrm{T}(p=0.01)$ were significant predictors of physical activity volume, while $S H 2 B 1$ (rs7498665) A $>$ G trended towards significance $(p=0.08) . \quad M C 4 R$ (rs17782313) $\mathrm{T}>\mathrm{C}$ explained $1.1 \%(p=0.02), T M E M 18$ (rs6548238) C>T explained $1.2 \%(p=0.01)$, and $S H 2 B 1$ (rs7498665) $\mathrm{A}>\mathrm{G}$ explained $0.6 \%(p=0.08)$ of the variability in physical activity volume.

\section{Genotype and Physical Activity Phenotype Associations MC4R (rs 17782313) T>C}

Subjects with the MC4R CC genotype spent $3.5 \%$ less MET-hour/week than T allele carriers $(p=0.02)$. Given the mean value of physical activity volume for the sample (Table 2), a $3.5 \%$ reduction in MET-hour/week among subjects with the $M C 4 R$ CC genotype equates to a 10.1 MET-hour/week decrease in physical activity volume for those with the CC genotype compared to $\mathrm{T}$ allele carriers.

\section{TMEM18 (rs6548238) C>T}

Subjects with the TMEM18 T allele spent $4.1 \%$ less MET-hour/week than those with the CC genotype ( $p=$ 0.01 ). Given the mean value of physical activity volume for the sample, (Table 2), a $4.1 \%$ reduction in METhour/week among TMEM18 T allele carriers equates to a 11.8 MET-hour/week decrease in physical activity volume for the $\mathrm{T}$ allele carriers compared to those with the CC genotype.

\section{SH2B1 (rs7498665) A>G}

Finally, subjects with the $S H 2 B 1$ GG genotype spent $3.6 \%$ less MET-hour/week than A allele carriers $(p=$ $0.08)$. Given the mean value of physical activity volume for the sample (Table 2), a $3.6 \%$ reduction among subjects with the SH2B1 GG genotype equates to 10.3 MET-hour/week decrease in physical activity volume for those with the GG genotype compared to A allele carriers.

Table 2 Subject characteristics and self-reported physical activity levels

\begin{tabular}{llll}
\hline Characteristics & Total sample & Women & Men \\
& $(n=492)$ & $(n=263)$ & $23.9 \pm 0.4$ \\
\hline Age (year) & $23.5 \pm 0.3$ & $23.2 \pm 0.4$ & $229)$ \\
Body mass index $(\mathrm{kg} / \mathrm{m})^{*}$ & $24.6 \pm 0.2$ & $23.9 \pm 0.3$ & $28.4 \pm 0.3$ \\
Physical activity volume (MET-hour/week) & $287.4 \pm 2.2$ & $288.5 \pm 2.7$ & $286.1 \pm 3.7$ \\
\hline
\end{tabular}

Values are presented as mean \pm standard error

${ }^{*} p=0.001$ (women vs men) 


\section{Discussion}

We tested six SNPs associated with obesity from GWAS by the GIANT consortium for their association with physical activity volume in the FAMuSS cohort. MC4R (rs17782313) $\mathrm{T}>\mathrm{C}(p=0.02)$ and TMEM18 (rs6548238) $\mathrm{C}>\mathrm{T}(p=0.01)$ were significant predictors of physical activity volume, while $S H 2 B 1$ (rs7498665) A $>$ G trended towards significance $(p=0.08)$. These GWAS obesityrelated genotype and physical activity volume associations accounted for $\sim 1 \%$ of the variance in the physical activity volume each. The genotype differences in physical activity volume that we found ranged from 10.1 to 11.8 MET-hour/week (i.e., 730 to $850 \mathrm{kcal} /$ week assuming a mean sample body weight of $72.3 \mathrm{~kg}$ ) and could theoretically amount to a weight differential of 10.8$12.7 \mathrm{lb}$ per year (i.e., assuming $3500 \mathrm{kcal}=1 \mathrm{lb}$ fat mass). Our results support the notion of genetic pleiotropy or the shared genetic influence among obesity and physical activity phenotypes that should be explored further [22]. Furthermore, the genotype differences we found in weekly physical activity volume have important public health implications for maintaining a healthy weight.

Our finding with $M C 4 R$ (rs17782313) $\mathrm{T}>\mathrm{C}$ and its association with physical activity is consistent with a prior report that this is an important obesity susceptibility genetic locus that also associates with physical activity. Loos et al. [32] examined whether MC4R (rs17782313) $\mathrm{T}>\mathrm{C}$ influenced self-reported physical activity among parents $(n=326,52 \pm 3.4$ years) and their offspring $(n=$ $343,28 \pm 8.7$ years) who were overweight in the Quebec Family Study. The parents with the MC4R (rs17782313) CC genotype reported engaging in $986.1 \mathrm{kcal} /$ week less in moderate-to-vigorous sports and recreation than subjects with the CT genotype and $1500.6 \mathrm{kcal} /$ week less than the $\mathrm{T}$ allele carriers. Similar to Loos et al. [32], FAMuSS subjects with the MC4R (rs17782313) CC genotype spent less weekly physical activity volume than $\mathrm{T}$ allele carriers. TMEM18 (rs6548238) $\mathrm{C}>\mathrm{T}$ and $S H 2 B 1$ (rs7498665) A $>$ G have not yet been examined for their associations with physical activity other than in the FAMuSS cohort, so comparisons to the published literature are not possible.

The biological mechanisms by which SNPs identified in GWAS to associate with obesity-related phenotypes may modulate physical activity are largely unknown. In addition, our findings are based on association and not causation. Nonetheless, as illustrated in Fig. 1, we propose two plausible explanations for the associations we observed: 1) an individual with genetic predispositions to obesity [16] is less physically active due to their obesity as discussed by Richmond et al [33] and others [34, 35] (Fig. 1b); or 2) an individual with genetic predispositions to be less physically active becomes overweight to obese (Fig. 1c). Although we acknowledge both explanations are possible, the biological features of the SNPs we examined appear to support the second explanation. In addition, Orkunoglu-Suer et al. [20] found that the same three SNPs that associated with physical activity volume in our study [i.e., MC4R (rs17782313) $\mathrm{T}>\mathrm{C}$, TMEM18 (rs6548238) C>T, and SH2B1 (rs7498665) $\mathrm{A}>\mathrm{G}$ ] also associated with body composition phenotypes including BMI among the FAMuSS cohort further substantiating the concept of pleiotropy and our hypothesis of the essential role that physical activity has in mediating overweight and obesity.

It is interesting to note that the three SNPs that we and Okkunoglu-Suer et al. [20] examined are expressed in brain and/or hypothalamus where energy homeostasis is regulated [16]. The hypothalamus is the primary output node for the limbic system, which is responsible for endocrine function and behavior reinforcement. The limbic system is implicated in the control of food procurement as an evolutionarily conserved survival mechanism to defend against famine [36]. In this regard, these three GIANT consortium identified GWAS obesity SNPs that we found to be associated with physical activity and Orkunoglu-Suer et al. found to be associated with body composition phenotypes [20] have been classified as hyperphagic genes related to appetite suppression and satiety whose regulation resides in the dopaminergic projection from the limbic system [37-39]. Recent research in animals suggests that the 'pleasure-reward' system residing in the dopaminergic pathway that regulates appetite and satiety has a key role in voluntary movement $[25,40]$ and heightened reward sensitivity in animals with obesity that binge eat [41, 42]. The apparent shared genetic influence of energy intake and expenditure whose regulation resides in similar central nervous system pathways, particularly in the hypothalamus and dopaminergic pathway, is noteworthy, supports our hypothesis, and merits further investigation.

This study has several limitations as this was a substudy of FAMuSS whose primary purpose was to examine the influence of genetic variation on the muscle size and strength response to resistance training. The FAMuSS cohort consisted primarily of healthy, EuropeanAmerican young adults with the characteristics of the subjects in this substudy mirroring those of the larger cohort (Table 3). The physical activity data we collected with the Paffenbarger physical activity questionnaire were susceptible to subject recall and social desirability bias [43], and there were no measures of reproducibility and validity about the Paffenbarger's questionnaire in our sample. However, the Paffenbarger physical activity questionnaire is a well validated and reliable method for assessing leisure time physical activity in similar populations to the present study [44]. Our only measure of body composition was BMI which does not discriminate among body fat, muscle 
Table 3 Genotype frequencies of single nucleotide polymorphisms for FAMuSS participants

\begin{tabular}{llllll}
\hline Gene & RefSeq\# & $\begin{array}{l}\text { Alleles } \\
(+/-)\end{array}$ & $\begin{array}{l}\text { Obesity } \\
\text { risk } \\
\text { allele }{ }^{a}\end{array}$ & $\begin{array}{l}\text { Obesity risk } \\
\text { allele } \\
\text { frequency in } \\
\text { FAMuSS }(+)\end{array}$ & $\begin{array}{l}\text { Published } \\
\text { obesity risk } \\
\text { allele frequency } \\
\text { for CEU }(+)^{b}\end{array}$ \\
\hline MC4R & rs17782313 & T/C & C & 0.790 & 0.735 \\
TMEM18 & rs6548238 & C/T & C & 0.824 & 0.850 \\
FTO & rs9939609 & T/A & A & 0.395 & 0.460 \\
NEGR1 & rs2815752 & A/G & A & 0.650 & 0.637 \\
SH2B1 & rs7498665 & A/G & G & 0.392 & 0.381 \\
KCTD15 & rs11084753 & G/A & G & 0.664 & 0.690 \\
\hline
\end{tabular}

CEU European Caucasian, SNPs single nucleotide polymorphisms, FAMuSS Functional SNPs Associated with Muscle Size and Strength, MC4R melanocortin 4 receptor, TMEM18 transmembrane protein 18, FTO fat mass and obesityassociated gene, NEGR1 neuronal growth regulator 1, SH2B1 Src homology 2B adapter protein 1, KCTD15 potassium channel tetramerization domain containing 15

${ }^{a}$ According to Willer et al. [16]

b Utah residents with northern western European ancestry from the Center for the Study of Human Polymorphisms (CEPH) collection used in haplotype map (HapMap)

mass, or bone [45]. Last, we did not measure energy intake nor did we obtain physiological data that would provide insight into mechanisms for the genotype-physical activity phenotype associations we found.

Yet, this study has several important strengths. FAMuSS is recognized as one of the largest exercise genomics studies ever conducted [46]. In addition, physical activity is more heritable among young than older adults [47]. Therefore, as the average age of the FAMuSS subjects was 24 years, the heritability of their habitual physical activity levels was not confounded with the influence of age that may have contributed to us finding the genotype-physical activity phenotype associations we observed.

\section{Conclusion}

In summary, we have shown that three genetic variants associated with obesity in GWAS by the GIANT consortium also associated with habitual physical activity in the FAMuSS cohort. These SNPs accounted for $\sim 1 \%$ of the variance in physical activity levels each. The genotype differences in physical activity volume we found ranged from 10.1 to $11.8 \mathrm{MET}$-hour/week equating to a potential weight differential of 10.8-12.7 lb annually. Our findings suggest obesity and physical activity have a shared genetic influence that is regulated by common central neural pathways that merit further investigation.

\section{Competing interests}

The authors declare that they have no competing interests.

\section{Authors' contributions}

$H L, G I A$, and LSP conceived the study, and wrote and revised the paper. TJA, PMG, NMM, PSV, RFZ, HGD, PDT, EPH, JMD, LSP participated in the design and performance of the study. JMD carried out the genetic analysis. HGD, VD, and MHC participated in statistical analyses and data interpretation. All authors participated in the drafting of this manuscript and have given final approval for publication.

\section{Acknowledgments}

The authors dedicate this manuscript to the honor and memory of their dear colleague and friend, Dr. Priscilla Clarkson. We thank Dr. Gyuhyeong Goh for helpful statistical consultation. This paper is supported by Functional Single Nucleotide Polymorphisms (SNPs) Associated with Human Muscle Size and Strength (FAMuSS) NIH R01 NS40606-02; 2001-2006, and the University of Connecticut, Center for Health, Intervention, and Prevention.

\section{Sources of support}

Supported by Functional Single Nucleotide Polymorphisms (SNPs) Associated with Human Muscle Size and Strength (FAMuSS) NIH R01 NS40606-02; 2001-2006 and the University of Connecticut Center for Health, Intervention, and Prevention.

\section{Author details}

'Department of Behavioral and Social Sciences, Brown University School of Public Health, Box G-S121-2, Providence, RI 02912, USA. ²Department of Kinesiology, University of Connecticut, Storrs, CT 06269, USA. ${ }^{3}$ Obesity Center \& School of Health Sciences, Emory \& Henry College, Marion, VA 24354, USA. ${ }^{4}$ Department of Health, Human Performance and Recreation, Baylor University, Waco, TX 76798, USA. ${ }^{5}$ Department of Sport Science and Health, Dublin City University, Dublin 7008802, Ireland. ${ }^{6}$ Exercise \& Sport

Performance, University of New England, Biddeford, ME 04005, USA. ${ }^{7}$ Department of Exercise Science and Health Promotion, Florida Atlantic University, Boca Raton, FL 33431, USA. ${ }^{8}$ Research Center for Genetic Medicine, Children's National Medical Center, Washington, DC 20010, USA. ${ }^{9}$ Department of Statistics, University of Connecticut, Storrs, CT 06269, USA.

${ }^{10}$ Division of Cardiology, Henry Low Heart Center, Hartford Hospital, Hartford, CT 06102, USA. ${ }^{11}$ Institute for Systems Genomics, University of Connecticut, Storrs, CT 06269, USA.

Received: 21 September 2015 Accepted: 21 September 2015 Published online: 15 October 2015

\section{References}

1. Ogden CL, Carroll MD, Kit BK, Flegal KM. Prevalence of childhood and adult obesity in the United States, 2011-2012. JAMA. 2014;311(8):806-14.

2. West DS, DiLillo V, Bursac Z, Gore SA, Greene PG. Motivational interviewing improves weight loss in women with type 2 diabetes. Diabetes Care. 2007;30(5):1081-7.

3. Patrick K, Raab F, Adams MA, Dillon L, Zabinski M, Rock CL, et al. A text message-based intervention for weight loss: randomized controlled trial. J Med Internet Res. 2009;11(1), e1.

4. Petry NM, Barry D, Pescatello L, White WB. A low-cost reinforcement procedure improves short-term weight loss outcomes. Am J Med. 2011;124(11):1082-5.

5. Christensen R, Kristensen PK, Bartels EM, Bliddal H, Astrup A. Efficacy and safety of the weight-loss drug rimonabant: a meta-analysis of randomised trials. The Lancet. 2007;370(9600):1706-13.

6. Donnelly JE, Hill JO, Jacobsen DJ, Potteiger J, Sullivan DK, et al. Effects of a 16-month randomized controlled exercise trial on body weight and composition in young, overweight men and women: the Midwest Exercise Trial. Arch Intern Med. 2003;163(11):1343-50

7. Jeffery RW, Epstein LH, Wilson GT, Drewnowski A, Stunkard AJ, Wing RR. Long-term maintenance of weight loss: current status. Health psychology. 2000;19(1S):5.

8. Donnelly JE, Blair SN, Jakicic JM, Manore MM, Rankin JW, Smith BK, et al. American College of Sports Medicine Position Stand. Appropriate physical activity intervention strategies for weight loss and prevention of weight regain for adults. Med Sci Sports Exerc. 2009;41(2):459-71.

9. Thompson WR, Pescatello LS, Gordon NF. ACSM's Guidelines for Exercise Testing and Prescription. 2010.

10. Haskell WL, Lee IM, Pate RR, Powell KE, Blair SN, Franklin BA, et al. Physical activity and public health: updated recommendation for adults from the American College of Sports Medicine and the American Heart Association. Med Sci Sports Exerc. 2007;39(8):1423-34. 
11. Rankinen T, Zuberi A, Chagnon YC, Weisnagel SJ, Argyropoulos G, Walts B, et al. The human obesity gene map: the 2005 update. Obesity. 2006;14(4):529-644.

12. Borjeson M. The aetiology of obesity in children. A study of 101 twin pairs. Acta Paediatr Scand. 1976;65(3):279-87.

13. Rice T, Borecki IB, Bouchard C, Rao DC. Segregation analysis of body mass index in an unselected French-Canadian sample: the Quebec Family Study. Obes Res. 1993;1(4):288-94.

14. Stunkard AJ, Foch T, Hrubec Z. A twin study of human obesity. JAMA. 1986;256(1):51-4

15. Bray MS, Sailors MH. The Interaction between Genetic Variation and Exercise and Physical Activity in the Determination of Body Composition and Obesity Status. In: Exercise Genomics. Volume Exercise Genomics. Edited by Pescatello LS, Roth SM. 233 Spring st, New York, NY 10013 USA: Human Press; 2011.

16. Willer CJ, Speliotes EK, Loos RJ, Li S, Lindgren CM, et al. Six new loci associated with body mass index highlight a neuronal influence on body weight regulation. Nat Genet. 2009;41(1):25-34.

17. Ahmad S, Rukh G, Varga TV, Ali A, Kurbasic A, Shungin DE, et al. Gene × physical activity interactions in obesity: combined analysis of 111,421 individuals of European ancestry. PLoS genetics. 2013;9(7), e1003607.

18. Li S, Zhao JH, Luan J, Ekelund U, Luben RN, Khaw KT, et al. Physical activity attenuates the genetic predisposition to obesity in 20,000 men and women from EPIC-Norfolk prospective population study. PLoS Med. 2010;7(8), e1000332.

19. Kilpelainen TO, Qi L, Brage S, Sharp SJ, Sonestedt E, Demerath E, et al. Physical activity attenuates the influence of FTO variants on obesity risk: a meta-analysis of 218,166 adults and 19,268 children. PLoS Med. 2011;8(11), e1001116.

20. Orkunoglu-Suer FE, Harmon BT, Gordish-Dressman H, Clarkson PM, Thompson PD, Angelopoulos TJ, et al. MC4R variant is associated with BMI but not response to resistance training in young females. Obesity. 2011;19(3):662-6.

21. Wagner GP, Zhang J. The pleiotropic structure of the genotype-phenotype map: the evolvability of complex organisms. Nature Reviews Genetics. 2011;12(3):204-13.

22. Solovieff N, Cotsapas C, Lee PH, Purcell SM, Smoller JW. Pleiotropy in complex traits: challenges and strategies. Nature Reviews Genetics. 2013;14(7):483-95.

23. Mathes WF, Nehrenberg DL, Gordon R, Hua K, Garland Jr T, Pomp D. Dopaminergic dysregulation in mice selectively bred for excessive exercise or obesity. Behav Brain Res. 2010;210(2):155-63.

24. Rhodes JS, Hosack GR, Girard I, Kelley AE, Mitchell GS, Garland Jr T. Differential sensitivity to acute administration of cocaine, GBR 12909, and fluoxetine in mice selectively bred for hyperactive wheel-running behavior Psychopharmacology (Berl). 2001;158(2):120-31.

25. Knab AM, Bowen RS, Hamilton AT, Gulledge AA, Lightfoot JT. Altered dopaminergic profiles: implications for the regulation of voluntary physical activity. Behav Brain Res. 2009;204(1):147-52.

26. Thompson PD, Moyna N, Seip R, Price T, Clarkson P, Angelopoulos T, et al. Functional polymorphisms associated with human muscle size and strength. Med Sci Sports Exerc. 2004;36(7):1132-9.

27. Harris JK, French SA, Jeffery RW, McGovern PG, Wing RR. Dietary and physical activity correlates of long-term weight loss. Obes Res. 1994;2(4):307-13.

28. Paffenbarger Jr RS, Wing AL, Hyde RT. Physical activity as an index of heart attack risk in college alumni. Am J Epidemiol. 1978;108(3):161-75.

29. Ainsworth BE, Haskell WL, Herrmann SD, Meckes N, Bassett Jr DR, Tudor-Locke C, et al. 2011 Compendium of Physical Activities: a second update of codes and MET values. Med Sci Sports Exerc. 2011;43(8):1575-81.

30. International HapMap Consortium. A haplotype map of the human genome. Nature. 2005;437(7063):1299-320.

31. Bassett Jr DR, Freedson P, Kozey S. Medical hazards of prolonged sitting. Exerc Sport Sci Rev. 2010;38(3):101-2.

32. Loos RJF, Lindgren CM, Li S, Wheeler E, Zhao JH, Prokopenko I, et al. Common variants near MC4R are associated with fat mass, weight and risk of obesity. Nat Genet. 2008;40(6):768-75.

33. Richmond RC, Davey Smith G, Ness AR, den Hoed M, McMahon G, Timpson NJ. Assessing causality in the association between child adiposity and physical activity levels: a Mendelian randomization analysis. PLoS Med. 2014;11(3), e1001618.
34. Metcalf BS, Hosking J, Jeffery AN, Voss LD, Henley W, Wilkin TJ. Fatness leads to inactivity, but inactivity does not lead to fatness: a longitudinal study in children (EarlyBird 45). Arch Dis Child. 2011;96(10):942-7.

35. Ekelund U, Brage S, Besson H, Sharp S, Wareham NJ. Time spent being sedentary and weight gain in healthy adults: reverse or bidirectional causality? Am J Clin Nutr. 2008;88(3):612-7.

36. Lenard NR, Berthoud HR. Central and peripheral regulation of food intake and physical activity: pathways and genes. Obesity. 2008;16 Suppl 3:S11-22.

37. Cecil JE, Tavendale R, Watt P, Hetherington MM, Palmer CN. An obesityassociated FTO gene variant and increased energy intake in children. $\mathrm{N}$ Engl J Med. 2008;359(24):2558-66.

38. Rask-Andersen M, Jacobsson JA, Moschonis G, Chavan RA, Sikder MA, Allzen $E$, et al. Association of TMEM18 variants with BMI and waist circumference in children and correlation of mRNA expression in the PFC with body weight in rats. Eur J Hum Genet. 2012;20(2):192-7.

39. Bauer F, Elbers CC, Adan RA, Loos RJ, Onland-Moret NC, Grobbee DE, et al. Obesity genes identified in genome-wide association studies are associated with adiposity measures and potentially with nutrient-specific food preference. Am J Clin Nutr. 2009;90(4):951-9.

40. Lightfoot JT. Current understanding of the genetic basis for physical activity. J Nutr. 2011;141(3):526-30.

41. Davis CA, Levitan RD, Reid C, Carter JC, Kaplan AS, Patte KA, et al. Dopamine for "wanting" and opioids for "liking": a comparison of obese adults with and without binge eating. Obesity. 2009;17(6):1220-5.

42. Davis JF, Tracy AL, Schurdak JD, Tschöp MH, Lipton JW, Clegg DJ, et al. Exposure to elevated levels of dietary fat attenuates psychostimulant reward and mesolimbic dopamine turnover in the rat. Behavioral Neuroscience; Behavioral Neuroscience. 2008;122(6):1257

43. Paulhus DL. Measurement and control of response bias. In: Robinson JP, Shaver PR, Wrightsman LS, editors. Measures of personality and social psychological attitudes. San Diego, CA: Academic; 1991. p. 17-59.

44. Albanes D, Conway JM, Taylor PR, Moe PW, Judd J. Validation and comparison of eight physical activity questionnaires. Epidemiology. 1990;1(1):65-71.

45. Ahima RS, Lazar MA. The Health Risk of Obesity- Better Metrics Imperative Science. 2013;341(6148):856-8.

46. Hagberg JM, Rankinen T, Loos RJ, Perusse L, Roth SM, Wolfarth B, et al. Advances in exercise, fitness, and performance genomics in 2010. Med Sci Sports Exerc. 2011;43(5):743-52.

47. Vink JM, Boomsma DI, Medland SE, de Moor MH, Stubbe JH, Cornes BK, et al. Variance components models for physical activity with age as modifier: a comparative twin study in seven countries. Twin Res Hum Genet. $2011 ; 14(1): 25-34$

\section{Submit your manuscript to a SpringerOpen ${ }^{\circ}$ journal and benefit from:}

- Convenient online submission

Rigorous peer review

- Immediate publication on acceptance

- Open access: articles freely available online

- High visibility within the field

- Retaining the copyright to your article

Submit your next manuscript at springeropen.com 